\title{
GANHO DE PESO E CARACTERÍSTICAS DE CARCAÇA DE BOVINOS NELORE E MEIO SANGUE ANGUS-NELORE EM REGIME DE SUPLEMENTAÇÃO A PASTO
}

\author{
Lucas Lopes Rino Dias ${ }^{1}$ \\ Carla Faria Orlandini ${ }^{2}$ \\ Denis Steiner ${ }^{2}$ \\ William Del Conte Martins ${ }^{2}$ \\ André Giarola Boscarato ${ }^{3}$ \\ Luiz Romulo Alberton**
}

DIAS, L. L. R.; ORLANDINI, C. F.; STEINER, D.; MARTINS, W. D. C.; BOSCARATO, A. G.; ALBERTON, L. R. Ganho de peso e características de carcaça de bovinos Nelore e meio sangue Angus-Nelore em regime de suplementação a pasto. Arq. Ciênc. Vet. Zool. UNIPAR, Umuarama, v. 18, n. 3, p. 155-160, jul./set. 2015.

\begin{abstract}
RESUMO: A pecuária de corte brasileira tem sido marcada por intensas transformações, resultantes da aplicação de técnicas modernas de produção, da utilização dos cruzamentos entre raças, e das exigências do mercado consumidor. O desempenho do período pré-desmama é importante por se tratar do primeiro resultado de produtividade animal e a classificação e tipificação das carcaças possibilitam enquadrá-las em diferentes classes e, assim, direcioná-las a diferentes mercados. O objetivo deste trabalho foi comparar o desempenho pré-desmama e características de carcaças entre dois grupos genéticos: Nelore (NE), e $1 / 2$ sangue Angus-Nelore (F1), os quais foram abatidos sem castração e suplementados a pasto do nascimento ao abate. Foram tomados, ao acaso, 36 animais sendo 18 machos da raça Nelore (NE) e 18 machos oriundos do cruzamento industrial entre Nelore e Angus, machos (F1), sendo todos submetidos ao mesmo manejo e abatidos sem castração, com idade aproximada de 20 meses. Durante o processo de abate, as carcaças foram classificadas e tipificadas. O grupo F1 foi superior ao grupo NE com diferença significativa referente ao peso ao nascer $(\mathrm{p}=0,0046)$, peso ajustado aos 205 dias $(\mathrm{p}=0,0002)$, peso ao desmame $(p=0,0005)$, ganho de peso diário entre o nascimento e os 205 dias $(p=0,001)$. Quanto às características de carcaças não houve diferença estatística entre os grupos ( $\mathrm{p}>0,05)$, sendo que, ambos atingiram a exigência frigorífica para espessura de gordura. Observou-se uma superioridade nos animais F1 quanto ao desempenho pré-desmama, e nota-se a possibilidade de terminar animais inteiros a pasto, com acabamento de carcaça mínimo, desde que bem alimentados.
\end{abstract}

PALAVRAS-CHAVE: Abate. Cruzamento industrial. Desempenho pré-desmama. Machos não castrados. Produtividade.

\section{WEIGHT GAIN AND CARCASS CHARACTERISTICS OF NELLORE AND CROSSBREED ANGUS-NELLORE CATTLE ON GRAZING SUPPLEMENTATION SCHEME}

\begin{abstract}
The Brazilian beef cattle industry has been marked by dramatic changes resulting from the application of modern production techniques, use of crossbreeding and consumer market requirements. The performance of the pre-weaning period is important because it is the first result of animal productivity, and the evaluation and classification of carcasses enable their categorization into different classes, and thus, their directing to different markets. The objective of this study was to compare the pre-weaning performance and carcass traits between two genetic groups: Nellore (NE) and Angus-Nellore crossbreed (F1), which were slaughtered without castration, receiving grazing supplementation from birth to slaughter. Thirty-six animals were randomly selected, 18 Nelore (NE) and 18 Angus-Nellore crossbreed (F1) animals, all males, submitted to the same management system and slaughtered without castration, with approximate age of 20 months. During the slaughtering process, carcasses were classified and typified. The F1 group was superior to the NE group with significant differences related to birth weight ( $p=0.0046)$, weight adjusted to 205 days $(p=0.0002)$, weaning weight $(p=0.0005)$, daily weight gain between birth and 205 days $(p=0.001)$. Regarding carcass traits, there was no statistical difference between groups $(p>0.05)$, and both reached the requirement for fat thickness. F1 animals were superior in relation to pre-weaning performance, and there is possibility to slaughter whole animals on pasture, with minimal carcass finishing if well fed.
\end{abstract}

KEYWORDS: Slaughter. Crossbreeding. Pre-weaning performance. Non-castrated males. Productivity.

\section{AUMENTO DE PESO Y CARACTERÍSTICAS DE ESQUELETO DE BOVINOS NELORE Y MEDIA SANGRE ANGUS-NELORE EN RÉGIMEN DE SUPLEMENTOS A PASTO}

RESUMEN: La pecuaria de corte brasileña ha sido marcada por intensas transformaciones, resultantes de la aplicación de técnicas modernas de producción, de utilización de los cruzamientos entre razas, y de exigencias del mercado consumidor. El desempeño del período pre destete es importante por tratarse del primer resultado de productividad animal, la clasifica-

\footnotetext{
${ }^{1}$ Residência em Clínica Médica e Cirúrgica de Grandes Animais, Universidade Estadual de Maringá (UEM), Umuarama, Paraná, Brasil.

${ }^{2}$ Mestrado em Ciência Animal, Universidade Paranaense (UNIPAR), Umuarama, Paraná, Brasil.

${ }^{3}$ Docente do Curso de Medicina Veterinária, UNIPAR, Umuarama, Paraná, Brasil.

${ }^{4}$ Docente do Curso de Medicina Veterinária e do Mestrado em Ciência Animal, UNIPAR, Umuarama, Paraná, Brasil. *Autor para correspondência: romulo@ unipar.br
} 
ción y tipificación de los esqueletos posibilitan encuadrarlos en diferentes clases y, así, dirigirlos a diferentes mercados. El objetivo de esa investigación ha sido comparar el desempeño pre destete y características de esqueletos entre dos grupos genéticos: Nelore (NE), y $1 / 2$ sangre Angus-Nelore (F1), los cuales fueron abatidos sin castración y suplementados a pasto desde el nacimiento al abate. Fueron tomados, al azar, 36 animales siendo 18 machos de la raza Nelore (NE) y 18 machos oriundos del cruzamiento industrial entre Nelore y Angus, machos (F1), siendo todos sometidos al mismo manejo y abatidos sin castración, con edad aproximada a 20 meses. Durante el proceso de abate, los esqueletos fueron clasificados y tipificados. El grupo $\mathrm{F} 1$ fue superior al grupo NE con diferencia significativa referente al peso al nascer $(\mathrm{p}=0,0046)$, peso ajustado a los 205 días $(p=0,0002)$, peso al destete $(p=0,0005)$, aumento de peso diario entre el nacimiento y los 205 días $(p=0,001)$. Sobre las características de esqueletos no hubo diferencia estadística entre los grupos $(\mathrm{p}>0,05)$, siendo que, ambos alcanzaron la exigencia frigorífica para espesor de grasa. Se observó una superioridad en los animales F1 en el desempeño pre destete, y se nota la posibilidad de terminar animales enteros a pasto, con terminación de esqueleto mínimo, desde que bien alimentados. PALABRAS CLAVE: Abate. Cruzamiento industrial. Desempeño pre destete. Machos no castrados. Productividad.

\section{Introdução}

A pecuária de corte brasileira tem sido marcada por diversas mudanças, principalmente nos setores técnicos, de saúde e de marketing, em consequência, principalmente, da aplicação de técnicas modernas de produção, da utilização dos cruzamentos e de uma estabilização da economia, os quais permitiram ao setor ganhos extraordinários de volume e produtividade e foram determinantes para colocar o Brasil em condição de destaque como um grande produtor de carne bovina (POLAQUINI; SOUZA; GEBARA, 2006). Com isso, intensificaram-se a formação de cadeias tecnificadas que buscam a diversificação de produtos e a que atendam novas exigências de diferentes mercados, trabalhando novos processos para antigas commodities agroindustriais (PASCOAL et al., 2011).

Diante desse quadro, a cadeia produtiva passa por uma nova etapa. A diferenciação de produtos, a começar pela classificação de carcaças, e a possível remuneração ao pecuarista pela melhor qualidade, certamente têm a produção de carne que atenda aos mercados interno e externo (POLAQUINI; SOUZA; GEBARA, 2006).

Segundo Euclides Filho (1997) o cruzamento em gado de corte proporciona características de produção desejáveis, sendo que, especialmente entre animais Bos indicus e Bos taurus, confere uma prática eficaz, com um produto precoce, de maior potencial de crescimento e acabamento de carcaça quando comparado ao Bos indicus, e maior adaptabilidade e maior resistência a parasitos quando comparados com Bos taurus. Nenhuma das raças puras, das duas espécies, apresentam essas características em conjunto.

Segundo Pereira e Muniz (2013) as características da pré-desmama são de grande importância econômica em bovinos de corte, uma vez que fornecem os primeiros dados sobre o desempenho do animal, além de se poder avaliar a habilidade materna. A classificação, juntamente com a avaliação da qualidade ou do rendimento, e ainda a padronização de carcaças são importantes por possibilitarem o atendimento aos mercados mais exigentes e que pagam mais, como é o caso da Cota Hilton, a qual consiste em 65.250 toneladas anuais de cortes especiais do quarto traseiro provenientes de animais jovens, livres da taxa de ingresso na Europa, divididos para países credenciados como o Brasil, responsável por 10.000 dessas, a fim de melhorar a eficiência produtiva e comercial da cadeia produtora de carne. Segundo Felício (2010) a Portaria Ministerial $n^{0} 612$, de 05 de outubro de 1989 continua em vigor para fins de exportação pela Cota Hilton.
$\mathrm{O}$ país precisa estar atento para atender às exigências do mercado consumidor, principalmente quanto à qualidade do produto final, ou seja, carcaça e carne. Para conquistar novos mercados e manter os já conquistados, a cadeia produtiva da carne bovina brasileira deve se organizar e se modernizar, visando à produção com eficiência, tanto técnica como econômica, e com qualidade (PACHECO et al., 2005).

Dessa forma, o objetivo deste trabalho foi comparar os resultados de desempenho pré-desmama e características de carcaças de dois grupos genéticos: machos Nelore (NE) e machos oriundos do cruzamento industrial (F1), 1/2 sangue Angus-Nelore, ambos inteiros, suplementados a pasto do nascimento ao abate.

\section{Material e Métodos}

Este estudo foi realizado nas fazendas Caçadinha e União, situadas em Rio Brilhante e Sidrolândia, respectivamente, no Mato Grosso do Sul, pertencentes à empresa Fabiani Saúde Animal. Foram tomados, ao acaso, 36 animais nascidos no mesmo período de parição, entre agosto e novembro de 2012, sendo 18 machos da raça Nelore (NE) e 18 machos oriundos do cruzamento industrial entre Nelore e Angus, machos (F1), a fim de comparar a eficiência produtiva dos grupos. Todos os animais foram submetidos ao mesmo manejo e abatidos sem castração, com idade aproximada de 20 meses. Os dois grupos foram formados por animais provenientes de inseminação artificial.

Os grupos NE e F1 foram manejados de forma a nascerem em pastos separados. Ao nascimento, os animais foram pesados e receberam os devidos cuidados neonatais, como cauterização do umbigo e a correta identificação, para cumprir as especificações da certificação. Durante o aleitamento, os bezerros receberam suplementação (creep-feeding), do nascimento aos 60 dias, composta por suplemento mineral para bezerros em fase de aleitamento ${ }^{1}$, ad libitum, e dos 60 dias até a desmama, uma mistura composta por milho $(57,4 \%)$, farelo de soja $(38,18 \%)$, sal $(0,9 \%)$, fosfato bicálcico $(1,68 \%)$, carbonato de cálcio $(0,64 \%)$ e suplemento mineral protéico vitamínico para bezerros de corte em fase de aleitamento $^{2}(1,20 \%)$.

Os animais foram desmamados seguindo um sistema racional, que consiste em manter algumas matrizes no rebanho e no mesmo pasto, por um período de 30 dias, amenizando desconfortos ocasionados paralelamente ao pro-

${ }^{1}$ Fosbovinho®, Tortuga Companhia Zootécnica Agrária, São Paulo - SP. ${ }^{2}$ Fosbovinho Protéico ADE®, Tortuga Companhia Zootécnica Agrária, São Paulo - SP. 
cesso convencional, como a alteração do habitat e perda da hierarquia, com idade aproximada de oito meses. Nesse período, houve a pesagem, posterior ajuste dos pesos da desmama para os 205 dias, e cálculo do ganho de peso diário do nascimento aos 205 dias. Após a desmama, os animais foram destinados à fase de recria, em sistema de pastejo com suplementação mineral e proteico-energética no cocho, mantendo a separação dos grupos. As pastagens utilizadas eram formadas por Brachiaria brizantha, provenientes da integração lavoura-pecuária, sendo o primeiro ano da pecuária após o ciclo da lavoura. A suplementação era composta pelos seguintes ingredientes: milho $(24,1 \%)$, soja $(58 \%)$, uréia $(2,5 \%)$, sal $(2,0 \%)$, fosfato bicálcico $(2,2 \%)$, carbonato de cálcio $(1,2 \%)$, e suplemento mineral para bovinos de corte em fase de recria ${ }^{3}(10,0 \%)$, com consumo diário aproximado de $0,5 \%$ do peso vivo de matéria seca.

Quando esses animais entraram no período de terminação, aproximadamente quatro meses antes do abate, foram submetidos a uma nova dieta composta por: milho $(83,4 \%)$, soja $(10 \%)$, uréia $(2,4 \%)$, e suplemento mineral nitrogenado vitamínico, contendo monensina sódica e leveduras vivas para animais confinados ${ }^{4}(4,2 \%)$, com consumo diário aproximado de $1 \%$ do peso vivo de matéria seca. Após este período, os animais foram pesados e transportados para o frigorífico, ainda inteiros, por meio de caminhões, realizando a pesagem após quatro horas de jejum e o abate após 17 horas. Durante o processo de abate, as carcaças foram classificadas e tipificadas, ainda quentes, depois da pesagem e antes de entrarem na câmara fria, conforme os critérios técnicos da Portaria $\mathrm{n}^{\circ} 612$ de 05 de outubro de 1989, do Ministério da Agricultura, seguindo o sistema BRASIL (B - carcaça ideal; R e A - intermediário; S, I e L - inferior) para posteriormente enquadrá-las em seus respectivos mercados de destino.

A classificação considerou a separação por gênero, conforme os caracteres sexuais (todos os animais do presente estudo eram machos inteiros), idade, considerando a erupção dos dentes incisivos permanentes ( 0 a 8 ), e peso mínimo de carcaça quente segundo a especificação por gênero $(210 \mathrm{~kg}$ para animais inteiros).

Após a classificação, as carcaças foram separadas em tipos de melhor para pior, conforme o acabamento, o qual consistiu em aferir a gordura em três locais diferentes: altura da sexta costela (sobre o músculo grande dorsal, em sua parte dorsal), altura da nona costela (sobre o músculo grande dorsal, em sua parte ventral) e altura da $12^{\mathrm{a}}$ costela (sobre o músculo serrátil dorsal caudal). As carcaças foram submetidas à seguinte classificação: 1: Magra - gordura ausente, 2: Gordura Escassa - 1 a 3 mm, 3: Gordura Mediana - 3 a 6 mm, 4: Gordura Uniforme - 6 a 10 mm, 5: Gordura Excessiva - acima de $10 \mathrm{~mm}$. A conformação, que é um parâmetro utilizado para demonstrar o desenvolvimento das massas musculares pela verificação dos perfis, adotou a seguinte descrição: C: Convexas, Sc: Subconvexas, Re: Retilíneas, Sr: Sub-retilíneas, Co: Côncavas. Na sequência comparou-se a classificação e tipificação entre os grupos, exemplificado na Tabela 1. Com o peso de carcaça quente e o peso de abate foi possível calcular o rendimento de carcaça.

${ }^{3}$ Foscromo ${ }^{\circledR}$, Tortuga Companhia Zootécnica Agrária, São Paulo - SP. ${ }^{4}$ Fosbovi Confinamento com Leveduras ${ }^{\circledR}$, Tortuga Companhia Zootécnica Agrária, São Paulo - SP.
Tabela 1: Exigências da Portaria Ministerial no 612, de 05 de outubro de 1989 para machos inteiros (M) conforme o tipo, este último representado pelas letras BRASIL.

\begin{tabular}{lcccc}
\hline Tipo & $\begin{array}{c}\text { Maturidade } \\
\left.\text { (d.i.p. }{ }^{1}\right)\end{array}$ & $\begin{array}{c}\text { Peso de carcaça } \\
\text { quente }(\mathbf{k g})\end{array}$ & Grau de acabamento & Conformação \\
\hline $\mathrm{B}$ & 0 & 210 & $2 / 3 / 4$ & $\mathrm{C} ; \mathrm{Sc} ; \mathrm{Re}$ \\
$\mathrm{A}$ & 0 & 210 & 1 e 5 & $\mathrm{Sr}$ \\
$\mathrm{I} / \mathrm{L}$ & $2-8$ & Sem restrições & Sem restrições & $\mathrm{Sr}$ e Co \\
\hline
\end{tabular}

${ }^{1}$ Dentes incisivos permanentes.

Os resultados obtidos foram comparados estatisticamente entre os grupos, utilizando o software Biostat 5.3, sendo que para a comparação dos resultados de peso ao nascimento, peso ajustado aos 205 dias, peso ao desmame, ganho de peso diário entre o nascimento e 205 dias, e rendimento de carcaça quente, utilizou-se o teste T, de Student, ao nível de $1 \%$. Já para cobertura de carcaça e maturidade, utilizou-se o teste Mann-Whitney, e para a proporção de animais desclassificados do tipo B, foi utilizado o teste Qui-quadrado.

\section{Resultados}

O desempenho do grupo F1 foi superior ao grupo $\mathrm{NE}$ com diferença significativa referente ao peso ao nascer $(p=0,0046)$, peso ajustado aos 205 dias $(p=0,0002)$, peso ao desmame $(\mathrm{p}=0,0005)$ e ganho de peso diário entre o nascimento e os 205 dias ( $p=0,001)$. Entretanto, observou-se que o rendimento de carcaça dos animais $\mathrm{F} 1$ foi inferior ao dos animais NE, embora sem significância estatística $(\mathrm{p}>0,05)$ (Tabela 2).

Tabela 2: Comparação do desempenho de dois grupos (NE X F1) de animais machos inteiros contemporâneos criados em sistema de suplementação a pasto e abatidos aos 20 meses de idade

\begin{tabular}{lccccc}
\hline Grupo & PN & P205 & PD & GPD & RC\% \\
\hline NE & $31,05 \pm 3,65$ & $171,61 \pm 16,30$ & $232,22 \pm 19,15$ & $0,683 \pm 0,08$ & $53,61 \pm 2,22$ \\
F1 & $34,33 \pm 2,76$ & $202,16 \pm 26,22$ & $272,78 \pm 38,41$ & $0,821 \pm 0,14$ & $52,50 \pm 1,54$ \\
\hline Teste T & $\mathrm{P}=0,0046$ & $\mathrm{P}=0,0002$ & $\mathrm{P}=0,0005$ & $\mathrm{P}=0,001$ & $\mathrm{P}=0,09$
\end{tabular}

$\mathrm{PN}$ - peso ao nascer;

P205 - peso ajustado aos 205 dias

$\mathrm{PD}$ - peso ao desmame

GPD - ganho de peso diário entre o nascimento e 205 dias

$\mathrm{RC} \%$ - rendimento de carcaça quente

$\mathrm{p}>0,05$ demonstra que não houve diferença estatística

Não foram observadas diferenças estatísticas quanto ao rendimento de carcaça quente entre os grupos NE X F1.

Apesar da totalidade dos animais do grupo F1 ainda não realizarem a troca dentaria dos incisivos (d.i.p.), a diferença com o NE não foi significativa. O acabamento de gordura nas carcaças nos dois grupos foi semelhante - maioria gordura escassa (Tabela 3), demonstrando um perfil de animais jovens e com acabamento mínimo.

A maioria dos animais, de ambos os grupos, alcançaram as exigências para carcaças tipo B, conforme a Portaria Ministerial $n^{\circ} 612$, de 05 de outubro de 1989, quanto aos quesitos peso e conformação de carcaça, sendo a gordura de cobertura e a maturidade, os únicos fatores que as desclassificaram, pois uma carcaça do grupo F1 apresentou escore "um” para gordura (mínimo de dois) e uma carcaça do grupo 
NE apresentou dois dentes incisivos permanentes, não sendo tolerado dentes permanentes em animais inteiros (Tabelas 3 e 4).

Tabela 3: Classificação de carcaças frigoríficas de dois grupos (NE X F1) de animais machos inteiros, suplementados a pasto e abatidos aos 20 meses de idade, conforme Portaria Ministerial $n^{\circ} 612$, de 05 de outubro de 1989.

\begin{tabular}{lll}
\hline Grupo & Gordura de Cobertura & Maturidade \\
\hline Nelore & $94,12 \%(17 / 18)-$ Escassa & $88,88 \%(16 / 18)-0$ d.i.p. \\
& $5,88 \%(01 / 18)-$ Mediana & $12,22 \%(02 / 18)-2$ d.i.p. \\
\hline F1 & $83,33 \%(15 / 18)-$ Escassa & $100 \%(18 / 18)-0$ d.i.p. \\
& $11,11 \%(02 / 18)-$ Mediana & \\
& $5,55 \%(01 / 18)-$ Ausente & \\
\hline Mann-Whitney & $\mathrm{P}=0,987$ & $\mathrm{P}=0,569$ \\
\hline
\end{tabular}

$\mathrm{p}>0,05$ demonstra que não houve diferença estatística

Tabela 4: Relação de animais machos inteiros, suplementados a pasto, abatidos aos 20 meses e tipificados conforme a Portaria Ministerial n ${ }^{\circ}$ 612, de 05 de outubro de 1989 (BRASIL).

\begin{tabular}{lll}
\hline Grupo & Tipo & Quantidade (\%) \\
\hline Nelore & $\mathrm{B}$ & $88,88 \%$ \\
& $\mathrm{I}$ & $12,22 \%$ \\
F1 & $\mathrm{B}$ & $94,44 \%$ \\
& $\mathrm{~A}$ & $5,55 \%$ \\
\hline Qi-quadrado & & $\mathrm{P}=0,1025$
\end{tabular}

Embora um maior número de carcaças desclassificadas do tipo B no grupo NE (02) comparada ao F1 (01), não houve diferença estatística $(\mathrm{p}>0,05)$.

\section{Discussão}

Conforme Mariani et al. (2009) o objetivo de se ajustar o peso de bezerros desmamados para 205 dias consiste em amenizar os defeitos de amostragem por meio da uniformização dos dados.

Milagres (1987) ressalta a importância da avaliação do peso ao nascimento, fato que permite avaliar criteriosamente o ganho de peso nas idades posteriores, bem como determinar os pesos máximos, a fim de evitar partos distócicos. $\mathrm{O}$ autor também relata a importância da avaliação do peso ao desmame, devido à possível comercialização nesta fase, correlação com crescimento ponderal futuro, e avaliação da habilidade materna das vacas do rebanho. Ainda de acordo com Milagres (1987), um rebanho de corte contendo bezerros com elevados níveis de ganho médio diário, no período pré-desmama, está relacionado a um período de nascimento ao abate mais curto, e uma maior eficiência produtiva.

Similarmente aos resultados encontrados no presente trabalho, Cubas et al. (2001) encontraram valores em animais $1 / 2$ sangue Angus-Nelore para ganho de peso diário e peso ao desmame, respectivamente, $117 \mathrm{~g}$ e $26 \mathrm{~kg}$, sendo superiores a animais Nelore, embora não foram observadas diferenças estatísticas no peso ao nascimento. Este resultado pode ser explicado pela escolha do touro no momento da inseminação, uma vez que ambos os trabalhos estudaram animais fruto dessa prática.

Marcondes et al. (2011) também relataram maior eficiência produtiva para animais Bos taurus/Bos indicus quando comparados a animais zebuínos puros, com o ganho de peso diário superior até os 205 dias, concordando com os dados desta pesquisa.

Conforme Magnabosco et al. (2013) há uma tendência linear e positiva para touros de elevados valores genéticos transmitirem suas características à sua prole, proporcionando um melhoramento genético, desde que efetuado criteriosamente. Segundo Mamede (2012), que avaliou o componente genético pelo desempenho de progênies em teste de desempenho de touros jovens, a seleção de animais para características pré e pós-desmama podem levar a incremento desses resultados, sendo que animais selecionados para ganho de peso pré-desmama propiciam uma diminuição do tempo gasto após a desmama até a terminação.

Segundo Silva, Pedrosa e Fraga (2008) os bezerros $1 / 2$ sangue Angus-Nelore demonstraram superioridade a animais Nelore quanto ao peso aos 210 dias e ao ganho de peso diário do nascimento aos 210 dias, em sistema de regime extensivo. Zamboni (2010) relata que as matrizes Nelore produzem menor quantidade de leite, influenciando o desempenho pré-desmama, porém, neste estudo, este efeito foi minimizado devido à suplementação dos bezerros.

Segundo Pereira e Muniz (2013) a prática de suplementar bezerros lactantes pode diminuir o efeito da idade da mãe sobre o desempenho destes animais. De acordo com Monção et al. (2013), o emprego correto desta prática proporciona o desenvolvimento da extensão ruminal e o crescimento das papilas.

Kippert (2008) não observou diferenças estatísticas entre os resultados de desempenho na fase pré-desmama em animais da raça Nelore comparado a animais $1 / 2$ sangue Angus-Nelore, em ambiente que não supriu as exigências nutricionais desses animais, em período de escassez, impossibilitando, assim, a expressão do seu potencial genético. Com isso, demonstra-se a importância da interação genética-ambiente, bem como da escolha de um material genético adaptado às condições ambientais e de manejo oferecidas aos animais. Os animais $1 / 2$ sangue do presente estudo, os quais tiveram interação positiva com a relação genética-ambiente, demonstrando resultados superiores ao grupo Nelore. Segundo Queiroz et al. (2009) a genética da raça Nelore impossibilita elevados resultados pré-desmama e animais cruzados são superiores a animais puros devido a expressão da heterose.

Conforme Corrêa, Dionello e Cardoso (2007) é fundamental ponderar a interação genética-ambiente, priorizando a escolha de material genético adequado às condições climáticas e do sistema de criação, principalmente ao optar por material genético importado, pois somente com esta interação ocorre a expressão do potencial genético, sendo preferível, segundo os autores, animais geneticamente inferiores e melhor adaptados à animais superiores e não adaptados.

Segundo Soutello et al. (2003) o abate de animais jovens proporciona um giro maior do capital para o produtor, melhorando o aproveitamento, bem como o aumento da taxa de desfrute da propriedade, influenciando, também, o incremento na qualidade da carne.

Conforme Costa et al. (2002), o peso de carcaça e o rendimento de carcaça são medidas de interesse dos frigoríficos, para avaliação do valor do produto adquirido e dos custos operacionais, visto que carcaças com pesos diferentes demandam mesma mão de obra e mesmo tempo de processa- 
mento. Conforme relatado por Santos et al. (2008), carcaças com melhor conformação são preferidas pelos frigoríficos e açougues, pois estão associadas à maior hipertrofia muscular e maior rendimento de carne na desossa.

Ferreira et al. (2011) também não encontraram diferenças entre grupos genéticos de novilhos abatidos aos 25 meses em um mesmo tratamento, quanto às características de carcaça, possivelmente, por esses ainda estarem em fase de crescimento. Esses autores catalogaram resultados baixíssimos (subcôncavo) para conformação de carcaça, enquanto que no presente estudo os resultados para o mesmo quesito foram razoáveis (retilíneas), demonstrando superioridade genética e/ou melhores condições de manejo.

Restle, Grassi e Feijó (1996) estudaram o desempenho a pasto de animais inteiros e observaram maior ganho de peso e ganho médio diário. Porém, bovinos castrados, independentemente do método de castração adotado, tiveram maior proporção de traseiro e maior porcentagem de gordura na carcaça. Alguns autores relatam que a testosterona é responsável por outras características relacionadas ao dimorfismo sexual, que prejudicam algumas características da carcaça, como o aumento da proporção do quarto dianteiro. Portanto, este fator pode interferir no aspecto comercial da carcaça, já que os cortes dessa região são menos valorizados, quando comparados aos cortes do quarto traseiro (cortes nobres da carcaça).

Souza et al. (2012) notaram diferenças entre grupos genéticos quanto a deposição de gordura subcutânea, sendo que o grupo de novilhas Angus apresentou maiores resultados que o grupo das raças Simental e Nelore. Isto ocorreu pelo fato de a raça Angus expressar a maturidade fisiológica primeiramente, uma vez que apresenta maior precocidade quando comparada as outras duas raças. Dessa forma, pode-se constatar que os animais do presente estudo ainda não haviam atingido a maturidade sexual (Tabela 3), sendo todos animais com idade aproximada a 20 meses, justificando a ausência de diferenças quanto ao grau de acabamento.

Menezes et al. (2014) estudaram o efeito da suplementação na proporção de $1 \%$ do peso vivo e observaram melhor cobertura de carcaça, corroborando com os resultados obtidos no presente estudo.

\section{Conclusão}

Nas condições em que o experimento foi desenvolvido, pode-se concluir que os animais do grupo $1 / 2$ sangue Angus-Nelore demonstraram superioridade em relação aos animais Nelore, quanto ao peso ao nascer, peso à desmama, aos 205 dias, e ganho de peso médio diário. Já com relação ao rendimento e características das carcaças os desempenhos foram semelhantes.

\section{Referências}

BRASIL. Portaria n. 612. Sistema Nacional de Tipificação de Carcaças Bovinas. Diário Oficial da União de 10.10.1989. Ministério da Agricultura, Pecuária e Abastecimento, 1989.

CORRÊA M. B. B.; DIONELLO, N. J. L.; CARDOSO, F. F. Efeito da interação genótipo-ambiente na avaliação genética de bovinos de corte. Revista Brasileira de Agrociência, Pelotas, v. 13, n. 2, p. 153-159, 2007.

COSTA, E. C. et al. Características da carcaça de novilhos Red Angus superprecoces abatidos com diferentes pesos.

Revista Brasileira de Zootecnia, Viçosa, v. 31, n. 1, p. 119-128, 2002.

CUBAS, A. C. et al. Desempenho até a desmama de bezerros nelore e cruzas com nelore. Revista Brasileira de Zootecnia, Viçosa, v. 30, n. 3, p. 694-701, 2001.

FELÍCIO, P. E. Classificação e tipificação de carcaças bovinas. In: PIRES, A. V. Bovinocultura de corte. 2. ed. Piracicaba: FEALQ, 2010. p. 1263-1282.

FERREIRA, E. T. et al. Terminação de novilhos de corte Angus e mestiços em pastagem natural na região da Campanha do RS. Revista Brasileira de Zootecnia, Viçosa, v. 40, n. 9, p. 2048-2057, 2011.

EUCLIDES FILHO, K. E. O melhoramento genético e os cruzamentos em bovino de corte. Campo Grande: Embrapa Gado de Corte, n. 63, 1997. Disponível em: <http://www.cnpgc.embrapa.br/publicacoes/doc/doc63/ index.html>. Acesso em: 27 out. 2014.

KIPPERT, C. J. et al. Efeitos genéticos aditivos diretos e maternos heterozigóticos sobre os desempenhos pré e pósdesmama em uma população multirracial Aberdeen Angus x Nelore. Revista Brasileira de Zootecnia, Viçosa, v. 37, n. 8, p. 1383-1391, 2008.

MAGNABOSCO, C. U. et al. Utilização de touros geneticamente avaliados como ferramenta para melhorar a produtividade de sistemas de bovinos de corte. Revista Colombiana de Ciências Pecuárias, Colômbia, v. 26, p. 284-291, 2013.

MAMEDE, M. M. S. Contribuição do componente genético de touros da raça Nelore avaliados pelo desempenho de suas progênies em teste de desempenho de touros jovens. Goiânia, 2012. 66 f. Dissertação (Mestrado) - Universidade Federal de Goiás.

MARCONDES, M. I. et al. Eficiência alimentar de bovinos puros e mestiços recebendo alto ou baixo nível de concentrado. Revista Brasileira de Zootecnia, Viçosa, v. 40, n. 6, p. 1313-1324, 2011.

MARIANI, P. et al. Avaliação do ganho de peso ajustado para 205 dias em bezerros da raça nelore e mestiços nelore $\mathrm{x}$ red angus, submetidos ao desmame temporário. Revista Acadêmica: Ciências Agrárias e Ambientais, Curitiba, v. 7, n. 4, p. 407-413, 2009.

MENEZES, L. F. de. et al. Aspectos qualitativos da carcaça e carne de novilhos superjovens da raça Devon, terminados em pastagem tropical, recebendo diferentes níveis de concentrado. Semina: Ciências Agrárias, Londrina, v. 35, n. 3, p. 1557-1568, 2014. 
MILAGRES, J. C. Seleção dentro de rebanho: gado de corte. Campo Grande: EMBRAPA-CNPGC, 1987. (Circular Técnica, n. 21). Disponível em: <http://www. cnpgc.embrapa.br/publicacoes/ct/ct21/index.html>. Acesso em: 27 out. 2014.

MONÇÃO, F. P. et al. Desenvolvimento da microbiota ruminal de bezerros: revisão de literatura. Revista Unimontes Científica, Montes Claros, v. 15, n. 1, p. 76-89, 2013.

PACHECO, P. S. et al. Características quantitativas da carcaça de novilhos jovens e superjovens de diferentes grupos genéticos. Revista Brasileira de Zootecnia, Viçosa, v. 34, n. 5, p. 1666-1677, 2005.

PASCOAL, L. L. et al. Relações comerciais entre produtor, indústria e varejo e as implicações na diferenciação e precificação de carne e produtos bovinos não-carcaça. Revista Brasileira de Zootecnia, Viçosa, v. 40, supl. especial, p. 82-92, 2011.

PEREIRA, A. M. V. S.; MUNIZ, C. A. S. D. Efeitos ambientais sobre características pré-desmama em bovinos da Raça Nelore Mocha. Semina: Ciências Agrárias, Londrina, v. 34, n. 1, p. 359-366, 2013.

POLAQUINI, L. E. M.; SOUZA, J. G.; GEBARA, J. J. Transformações técnico-podutivas e comerciais na pecuária de corte brasileira a partir da década de 90 . Revista Brasileira de Zootecnia, Viçosa, v. 35, n. 1, p. 321-327, 2006.

QUEIROZ, S. A. et al. Efeitos ambientais e genéticos sobre escores visuais e ganho de peso à desmama de animais formadores da raça Brangus. Revista Brasileira de Zootecnia, Viçosa, v. 38, n. 2, p. 277-283, 2009.

RESTLE, J.; GRASSI, C.; FEIJÓ, G.L.D. Características das carcaças e da carne de bovinos inteiros ou submetidos a duas formas de castração, em condições de pastagem. Revista Brasileira de Zootecnia, Viçosa, v. 25, n. 2, p. 334-344, 1996.

SANTOS A. P. et al. Características quantitativas da carcaça de novilhos jovens e superjovens com peso de abate similares. Ciência Animal Brasileira, Goiânia, v. 9, n. 2, p. 300-308, 2008.

SILVA, F. L.; PEDROSA, A. C.; FRAGA, A. B. Desempenho de bezerros Nelore e cruzados no estado de Alagoas. Revista Científica de Produção Animal, Areia, v. 10, n. 1, p. 21-27, 2008.

SOUTELLO, R. V. G. et al. Idade ao abate de bovinos em frigorífico no município de Andradina-SP. Revista Ciências Agrárias e da Saúde, Andradina, v. 3, n. 1, p. 11-18, jan./ jun., 2003.

SOUZA, E. J. O. et al. Taxa de deposição de tecidos corporais de novilhas Nelore e suas cruzas com Angus e Simental. Revista Brasileira de Saúde e Produção

Animal, Salvador, v. 13, n. 2, p. 344-359, 2012.

ZAMBONI, V. T. Correlação entre escores visuais

de conformação e indicadores de desempenho, características de carcaça e de carne de novilhos Nelore e cruzados Aberdeen Angus x Nelore. Araçatuba, 2010. 91 f. Dissertação (Mestrado) - Universidade Estadual Paulista.

Recebido em: 30.09 .2015 Aceito em: 11.11.2015 